\title{
Patient preferences for lifestyle behaviours in osteoporotic fracture prevention: a cross-European discrete choice experiment
}

\author{
C. Beaudart ${ }^{1}$ (D) A. Boonen ${ }^{2} \cdot$ N. Li ${ }^{1} \cdot$ S. Bours ${ }^{1} \cdot$ S. Goemaere ${ }^{3} \cdot$ J.-Y. Reginster ${ }^{4} \cdot$ C. Roux ${ }^{5} \cdot$ B. McGowan ${ }^{6}$. \\ A. Diez-Perez ${ }^{7} \cdot$ R. Rizzoli ${ }^{8} \cdot$ C. Cooper ${ }^{9} \cdot$ M. Hiligsmann ${ }^{1}$
}

Received: 15 October 2021 / Accepted: 12 January 2022 / Published online: 26 January 2022

(c) The Author(s) 2022

\begin{abstract}
Summary Using a discrete choice experiment, we aimed to assess patients' preferences with regard to adopting lifestyle behaviours to prevent osteoporotic fractures. Overall, the 1042 patients recruited from seven European countries were favourable to some lifestyle behaviours (i.e., engaging in moderate physical activity, taking calcium and vitamin D supplements, reducing their alcohol consumption and ensuring a normal body weight).

Introduction Alongside medical therapy, healthy lifestyle habits are recommended for preventing osteoporotic fractures. In this study, we aimed to assess patients' preferences with regard to adopting lifestyle changes to prevent osteoporotic fractures. Methods A discrete choice experiment was conducted in seven European countries. Patients with or at risk of osteoporosis were asked to indicate to what extent they would be motivated to adhere to 16 lifestyle packages that differed in various levels of 6 attributes. The attributes and levels proposed were physical activity (levels: not included, moderate or high), calcium and vitamin D status (levels: not included, taking supplements, improving nutrition and assuring a minimal exposure to sunlight daily), smoking (levels: not included, quit smoking), alcohol (levels: not included, moderate consumption), weight reduction (levels: not included, ensure a healthy body weight) and fall prevention (levels: not included, receiving general advice or following a 1-day fall prevention program). A conditional logit model was used to estimate a patient's relative preferences for the various attributes across all participants and per country.

Results In total, 1042 patients completed the questionnaire. Overall, patients were favourable to lifestyle behaviours for preventing osteoporotic fractures. However, among the lifestyle behaviours proposed, patients were consensually not prone to engage in a high level of physical activity. In addition, in Ireland, Belgium, the Netherlands and Switzerland, patients were also not inclined to participate in a 1-day fall prevention program and Belgian, Swiss and Dutch patients were not prone to adhere to a well-balanced nutritional program. Nevertheless, we observed globally that patients felt positively about reducing their alcohol consumption, engaging in moderate physical activity, taking calcium and vitamin D supplements and ensuring a normal body weight, all measures aimed at preventing fractures.

Conclusions In a patient-centred approach, fracture prevention should take these considerations and preferences into account.
\end{abstract}

Keywords Discrete choice experiment $\cdot$ Fractures $\cdot$ Lifestyle $\cdot$ Osteoporosis $\cdot$ Patients' preferences

\section{Introduction}

Osteoporosis and related fractures are a major cause of morbidity and mortality in older people [1,2]. Since the incidence of osteoporosis is increasing each year and bone fractures are the third highest cause of becoming bedridden, maintenance of healthy bones is an important factor in

\section{Beaudart}

c.beaudart@maastrichtuniversity.nl

Extended author information available on the last page of the article extending a person's healthy lifespan [3]. To date, most of the evidence for osteoporosis treatment supports pharmacological intervention to improve bone mineral density and consequently bone health [4-6]. In 2019, Barrionuevo et al. [7] published a network meta-analysis showing the positive effects of more than 20 different pharmaceutical therapies on the prevention of vertebral fractures in postmenopausal women. Beside pharmaceutical therapies, healthy lifestyle habits are also recommended for preventing osteoporotic fractures by various respected scientific societies-for example, the International Osteoporosis Foundation (IOF), 
the European Society for Clinical and Economic Aspects of Osteoporosis, Osteoarthritis (ESCEO), the American College of Rheumatology (ACR), the American Society for Bone and Mineral Research (ASBMR) and the American Association of Clinical Endocrinologists (AACE) [6, 8-11].

Although bone density is largely determined by genetic factors, a number of lifestyle factors also play a role in the development or prevention of osteoporosis and osteoporosisrelated fractures, through their effects on bone development during years of growth and the rate of bone loss in later life. Numerous meta-research studies and expert consensus have highlighted the positive role of diet, physical activity and other healthy lifestyle behaviours in ensuring good skeletal health throughout life and preventing osteoporosis and osteoporosis fractures [12-15].

Despite the well-known role of healthy lifestyle habits on bone health and on health in general, many people do not heed the advice of their healthcare professionals and do not adopt recommended preventive health measures. Physician and patient factors play a role in explaining this implementation gap. From the patient's perspective, willingness to accept preventive strategies for bone health may be associated with multiple factors such as personal experience with osteoporosis, socioeconomic status, health literacy, communication and one's relationship with the healthcare professional, perceived confidence in one's own ability to change behaviour, including the ability to overcome barriers, lack of support from family/surroundings, work schedule or phycological distress [16-19]. It seems therefore essential to understand patient preferences and needs for optimal lifestyle management of the disease. Understanding and quantification of a patient's preferences regarding healthy lifestyle regimens may lead to tailored programs rather than using generic approaches. Individualised care can lead to improvement in patient satisfaction, in patient adherence to the healthy lifestyle habits, in patient health and ultimately in improved efficiency of healthcare system interventions.

Studies on patient preferences for adopting healthy lifestyle behaviours have been performed for other diseases such as diabetes [20], obesity [21] and for colorectal cancer survivors [22], but no such studies have been developed for a population of patients suffering from or at risk of osteoporosis. Accordingly, in this study, we aimed to understand patients' willingness to implement different regimens of lifestyle recommendation to prevent osteoporotic fractures.

\section{Methods}

\section{Discrete choice experiment (DCE)}

A DCE was used to examine patient preferences for lifestyle adaptations to prevent osteoporotic fractures. In the
DCE survey, patients were repetitively asked if (yes/no) they would closely implement 16 different lifestyle packages which were described by a set of attributes and levels (see below). By varying the levels within each attribute and question, scenarios for each choice were developed; these are referred to as choice sets. The DCE was developed according to the guidelines provided by the ISPOR Good Research Practice for Conjoint Analysis Task Force [23].

\section{Identification and selection of attributes and levels}

The attributes and levels were selected based on a scoping literature review and discussion/validation by a dozen experts in osteoporosis and/or preference research. The final list of attributes and levels is available in Table 1. Six attributes were used in the DCE. The attributes and levels presented in the choice sets were the following: physical activity (levels: not included, moderate or high), calcium and vitamin D status (levels: not included, taking supplements of vitamin D and calcium or adhering to a diet rich in milk products and fish and assuring a minimal daily exposure to sunlight), smoking (levels: not included or quit smoking), alcohol (levels: not included or moderate consumption), weight reduction (levels: not included or ensure a healthy body weight) and fall prevention (levels: not included, receive general advice or attend a 1-day prevention program). Common to each attribute was the level 'not included' (meaning this specific lifestyle behaviour would not be part of the lifestyle package).

If some categories were not relevant for respondents (for example 'quit smoking' when participant was already a nonsmoker), simply ignoring the attribute(s) was recommended.

\section{Experimental design}

The set of lifestyle recommendations to be presented to the respondents was based on an experimental design. Specifically, we used a Bayesian efficient design to maximise the D efficiency of the chosen choice sets using Ngene software (version 1.1.1, http://www.choicemetrics.com). A Bayesian efficient design aims to maximise the precision of the estimated parameters of the attributes for a given number of choice tasks by incorporating a priori information about the sign and value of parameters. Parameter estimates deriving from a pilot study $(n=10)$ were used as a priori information to construct the choice sets. Fifteen different choice tasks were created in which respondents were asked, in each case, to inform whether they would implement the lifestyle recommendation (yes/no). One of these choice tasks was repeated at the end of the choice tasks to assess the test-retest reliability of respondents' choices. Each respondent therefore received 16 choice tasks (these choice tasks are provided in 
Table 1 List of attributes and levels

\begin{tabular}{|c|c|}
\hline Attributes & Levels \\
\hline Physical activity & $\begin{array}{l}\text { Not included } \\
\text { Walking for 15-20 min, 1-2 times per week (or equivalent physical activity such as jogging, climbing stairs, } \\
\text { playing sports, doing aerobics or dancing) } \\
\text { Walking for 30-40 min, 3-4 times per week (or equivalent physical activity) }\end{array}$ \\
\hline Calcium and vitamin D status & $\begin{array}{l}\text { Not included } \\
\text { Supplements (taking daily calcium and vitamin D tablets) } \\
\text { Nutrition (a diet rich in milk products and fish: at least two milk products per day (e.g., milk, cheese, yogurt) and } \\
\text { fish at least two times per week) and exposure to sunlight (10 to } 15 \text { min per day, without using sunblock but } \\
\text { taking care to avoid sunburn by keeping out of the strong midday sun) }\end{array}$ \\
\hline Smoking & $\begin{array}{l}\text { Not included } \\
\text { Quit smoking }\end{array}$ \\
\hline Alcohol consumption & $\begin{array}{l}\text { Not included } \\
\text { Moderation (not more than } 2 \text { units of alcohol daily. A unit of alcohol is equivalent to a medium-sized glass of } \\
\text { wine, a tot of spirits or half a pint of beer) }\end{array}$ \\
\hline Body weight & $\begin{array}{l}\text { Not included } \\
\text { To ensure a healthy body weight (avoid becoming overweight or underweight) }\end{array}$ \\
\hline Fall prevention & $\begin{array}{l}\text { Not included } \\
\text { General advice (you receive a leaflet with general advice on avoiding falls, including removing objects from } \\
\text { around the house that increase risk of falling) } \\
\text { To participate in a fall prevention program (a 1-day course that teaches you about the avoidable circumstances in } \\
\text { which most people fall and also teaches you how to protect yourself when falling in order to reduce your risk of } \\
\text { fracture) }\end{array}$ \\
\hline
\end{tabular}

ESM Appendix 1). An example of a choice task is shown in Fig. 1.

\section{Questionnaire design}

Originally, the questionnaire included two DCEs; one to assess patient preferences for osteoporosis medical therapy (data already published [24]), and the present DCE to assess patient willingness to implement different regimens of lifestyle recommendation to prevent osteoporosis fractures. The questionnaire consisted of five parts: (1) a patient information leaflet and informed consent; (2) the DCE to elicit preferences for attributes of anti-osteoporosis drug therapy, (3) the DCE on lifestyle, including a description of the choice tasks, attributes, levels and an example of the choice task, and then the 16-choice tasks that participants had to fill in; (4) questions about the respondent's demographic (e.g., age, gender, height, weight and education level), years since diagnosis of osteoporosis and other characteristics that could affect the participant's willingness to accept lifestyle recommendations (e.g., physical activity level, nutrition, smoking and alcohol consumption) and (5) the difficulty of the task was estimated on a 7-point scale ( $1=$ extremely easy to 7 = extremely difficult).

The questionnaire was initially developed in English by a working group that included a patient, DCE experts and osteoporosis experts. The survey was then pilot-tested on a sample of 15 participants to check for any problems with interpretation and understanding. The questionnaire was then translated into three languages (French, Spanish and Dutch) by a medical translation company specialising in the translation of patient-reported outcome measures (Pharma Quest Ltd, Oxford, UK). Each translation was verified by our principal investigator for the country. The four languages

\begin{tabular}{|c|c|c|c|c|c|c|c|}
\hline Physical activity & $\begin{array}{c}\text { Calcium/Vitamin D } \\
\text { status }\end{array}$ & Smoking & $\begin{array}{c}\text { Alcohol } \\
\text { consumption }\end{array}$ & Body weight & $\begin{array}{c}\text { Falls } \\
\text { prevention }\end{array}$ & $\begin{array}{c}\text { Would you follow } \\
\text { the package of } \\
\text { recommendations } \\
\text { closely? }\end{array}$ \\
\hline \multirow{2}{*}{ Package A } & Not included & Daily supplements & Quit smoking & Not included & Not included & $\begin{array}{c}\text { Falls } \\
\text { prevention } \\
\text { program }\end{array}$ & $\begin{array}{c}\text { YES } \\
\text { No }\end{array}$ \\
\hline
\end{tabular}

Fig. 1 Example of choice task 
covered the languages spoken across the countries in our sample.

\section{Study population and data collection and ethical approval}

The study was conducted in seven European countries (Belgium, France, Ireland, the Netherlands, Spain, Switzerland and the UK) between March and October 2012. Patients with or at risk of osteoporosis to whom medication (or lifestyle behaviours) was at least proposed were consecutively recruited during outpatients' clinics. The questionnaire was completed by the patient at the clinic, or at home and returned in a postage-paid envelope.

Approval for this study was obtained from the Medical Ethics Committee of the Academic Hospital Maastricht and Maastricht University. A team from this university coordinated the project. Participants gave informed written consent according to the 1964 Helsinki declaration. Additional local ethics approval was obtained from those participating centres that required ethics approval for a DCE study, i.e., the Research Ethics Committee of Sligo University Hospital, the Southampton Joint Ethics Committee, the CEIC-Parc de Salut Mar (Committee of Ethics and Clinical Investigation) and the 'Commission cantonale d'éthique de la recherche' (CCER) of Geneva.

\section{Sample size}

Optimal sample size requirements for DCEs depend on the true value of the parameters estimated in the DCE, which are not known prior to undertaking the research [25]. For this reason, DCE sample size estimates are generally based on previous research, rule-of-thumb and budget constraints. Given the number of attributes included in the DCE, a minimum of 100 patients per country was targeted, which was sufficient based on common rule-of-thumb for minimum sample size [26].

\section{Statistical analyses}

Questionnaires were included in the analysis if a respondent completed all choice tasks. Respondent characteristics were analysed using descriptive statistics. The normality of the distribution of the quantitative parameters was investigated using the mean-median comparison, the histogram and quantile-quantile plot and tested with the Shapiro-Wilk hypothesis test. Results were expressed as numbers and frequencies for qualitative variables and as mean and standard deviation (SD) or median and interquartile range (IQR, P25-P75) for quantitative variables.

Data derived from the choice tasks were analysed using Nlogit software (version 5) to assess preferences for attributes and levels. A conditional logit regression model (i.e., multinomial model) was used to estimate patient preferences. We considered an attribute significant if a difference between at least two levels was significant. The model was run on the full study sample and per country. Subgroup analyses were also performed on gender (men vs women), age ( $<65$ years vs $\geq 65$ years), diagnosis of osteoporosis (yes vs no), fracture (yes vs no) and treatment for osteoporosis (yes vs no). Effect coding was used to describe the levels within an attribute. In using effect coding, mean attributes are normalised to zero and preference weights are relative to the mean effect of the different levels of the attribute. The model assumed that all attributes have an independent influence on patient preference(s). A positive (negative) sign for a given level indicates that a level has a positive (negative) effect on utility compared to the mean effect of the attribute. The higher the coefficient, the more effect the coefficient has. A 95\% CI around two levels that did not overlap indicated that the differences between the preference weights were statistically different.

In addition, the relative importance of attributes (in percentage) was calculated, using the range method for all participants and for the participants in each country. To calculate the relative importance of each attribute, the difference between the highest and the lowest coefficient for the levels of each attribute was divided by the sum of all attributes' specific level ranges.

\section{Results}

\section{Patients' characteristics}

Globally, a total of 1042 patients fully completed the questionnaire and were included in the analysis, with samples varying between 91 and 244 patients per country. Respondents' sociodemographic and health characteristics are presented in Table 2. The respondents had a mean age of 64.9 years, and $84.8 \%$ were female. Of all respondents, 73.3\% were diagnosed with osteoporosis, $52.9 \%$ were in treatment for osteoporosis and $48.2 \%$ reported a prevalent fracture. Most respondents reported that their current level of physical activity was high or moderate (i.e., $76.4 \%$ vs $24.6 \%$ with low activity level), that they were well-nourished and had a balanced diet (i.e., $65 \%$ vs $25 \%$ with a bad or very poorly balanced diet), that they did not smoke (i.e., $86.7 \%$ vs $13.3 \%$ were smokers) and that they did not drink 3 or more units of alcohol per day (i.e., $93.8 \%$ vs $6.2 \%$ who drank more). We investigated the participants' readiness to change and, among patients with a low level of physical activity, $21 \%$ were not ready to change; among patients with a poorly balanced diet, $22.1 \%$ were not ready to change; 
Table 2 Patient characteristics

\begin{tabular}{|c|c|c|c|c|c|c|c|c|}
\hline & $\begin{array}{l}\text { Total } \\
(n=1042)\end{array}$ & $\mathrm{UK}(n=97)$ & $\begin{array}{l}\text { Ireland } \\
(n=197)\end{array}$ & $\begin{array}{l}\text { Belgium } \\
(n=244)\end{array}$ & $\begin{array}{l}\text { the Neth- } \\
\text { erlands } \\
(n=169)\end{array}$ & $\begin{array}{l}\text { France } \\
(n=91)\end{array}$ & $\begin{array}{l}\text { Switzerland } \\
(n=98)\end{array}$ & Spain $(n=146)$ \\
\hline $\begin{array}{l}\text { Age (years, } \\
\text { mean } \pm \mathrm{SD})\end{array}$ & $64.9 \pm 11.0$ & $70.1 \pm 8.5$ & $64.0 \pm 12.0$ & $66.9 \pm 10.4$ & $65.3 \pm 10.8$ & $66.8 \pm 10.6$ & $62.5 \pm 9.3$ & $58.5 \pm 9.8$ \\
\hline Female (\%) & $84.8 \%$ & $91.7 \%$ & $86.7 \%$ & $80.8 \%$ & $78.2 \%$ & $90.9 \%$ & $81.1 \%$ & $90.7 \%$ \\
\hline $\begin{array}{l}\text { Height }(\mathrm{cm}, \\
\text { mean } \pm \mathrm{SD})\end{array}$ & $161.7 \pm 10.6$ & $160.6 \pm 9.2$ & $162.4 \pm 7.8$ & $159.8 \pm 13.1$ & $167.0 \pm 7.4$ & $159.2 \pm 12.8$ & $162.9 \pm 8.5$ & $159.3 \pm 10.7$ \\
\hline $\begin{array}{l}\text { Weight }(\mathrm{kg}, \\
\text { mean } \pm \mathrm{SD})\end{array}$ & $65.0 \pm 14.2$ & $63.6 \pm 14.7$ & $68.7 \pm 15.8$ & $63.8 \pm 12.5$ & $70.9 \pm 15.0$ & $58.1 \pm 10.0$ & $60.2 \pm 11.9$ & $64.0 \pm 13.8$ \\
\hline \multicolumn{9}{|c|}{ Educational level } \\
\hline Primary & $12.2 \%$ & $3.1 \%$ & $19.6 \%$ & $9.1 \%$ & $9.9 \%$ & $4.5 \%$ & $10.2 \%$ & $22.1 \%$ \\
\hline $\begin{array}{l}\text { Some high } \\
\text { school }\end{array}$ & $27.8 \%$ & $54.6 \%$ & $24.7 \%$ & $35.1 \%$ & $25.8 \%$ & $31.5 \%$ & $14.3 \%$ & $11.4 \%$ \\
\hline $\begin{array}{l}\text { High school } \\
\text { graduate }\end{array}$ & $29.5 \%$ & $19.6 \%$ & $29.9 \%$ & $29.8 \%$ & $37.1 \%$ & $13.5 \%$ & $36.7 \%$ & $31.4 \%$ \\
\hline $\begin{array}{l}\text { College or } \\
\text { university }\end{array}$ & $30.4 \%$ & $22.7 \%$ & $25.8 \%$ & $26.0 \%$ & $27.1 \%$ & $50.5 \%$ & $38.8 \%$ & $35.0 \%$ \\
\hline $\begin{array}{l}\text { Diagnosis of } \\
\text { osteoporosis }\end{array}$ & $73.3 \%$ & $93.8 \%$ & $45.4 \%$ & $89.1 \%$ & $71.1 \%$ & $94.3 \%$ & $93.3 \%$ & $47.5 \%$ \\
\hline $\begin{array}{l}\text { Years since } \\
\text { osteoporosis } \\
(\text { mean } \pm \mathrm{SD})\end{array}$ & $7.44 \pm 6.8$ & $8.8 \pm 6.5$ & $5.4 \pm 5.2$ & $8.0 \pm 6.1$ & $5.1 \pm 5.7$ & $8.9 \pm 8.9$ & $7.3 \pm 5.7$ & $8.3 \pm 9.1$ \\
\hline $\begin{array}{l}\text { With prior } \\
\text { fracture }\end{array}$ & $48.2 \%$ & $58.8 \%$ & $43.7 \%$ & $47.1 \%$ & $54.4 \%$ & $69.2 \%$ & $51.0 \%$ & $26.7 \%$ \\
\hline $\begin{array}{l}\text { Currently in } \\
\text { osteoporotic } \\
\text { treatment }\end{array}$ & $52.9 \%$ & $66.0 \%$ & $36.0 \%$ & $66.8 \%$ & $45.6 \%$ & $62.6 \%$ & $68.4 \%$ & $35.6 \%$ \\
\hline \multicolumn{9}{|c|}{ Current level of physical activity } \\
\hline Very active & $35.3 \%$ & $28.9 \%$ & $26.9 \%$ & $32.1 \%$ & $48.4 \%$ & $42.0 \%$ & $30.9 \%$ & $41.3 \%$ \\
\hline $\begin{array}{l}\text { Moderately } \\
\text { active }\end{array}$ & $45.1 \%$ & $58.8 \%$ & $46.7 \%$ & $43.5 \%$ & $34.6 \%$ & $47.7 \%$ & $50.5 \%$ & $42.0 \%$ \\
\hline $\begin{array}{l}\text { Occasionally } \\
\text { active }\end{array}$ & $12.5 \%$ & $7.2 \%$ & $17.3 \%$ & $12.2 \%$ & $10.5 \%$ & $9.1 \%$ & $11.3 \%$ & $15.2 \%$ \\
\hline Inactive & $7.1 \%$ & $5.2 \%$ & $9.1 \%$ & $12.2 \%$ & $6.5 \%$ & $1.1 \%$ & $7.2 \%$ & $1.4 \%$ \\
\hline \multicolumn{9}{|c|}{ Current nutrition } \\
\hline Very good & $26.6 \%$ & $44.8 \%$ & $38.6 \%$ & $22.0 \%$ & $16.1 \%$ & $22.5 \%$ & $26.3 \%$ & $19.6 \%$ \\
\hline Good & $68.4 \%$ & $52.1 \%$ & $58.4 \%$ & $73.0 \%$ & $78.1 \%$ & $71.9 \%$ & $68.4 \%$ & $73.2 \%$ \\
\hline $\mathrm{Bad}$ & $4.6 \%$ & $3.1 \%$ & $3.0 \%$ & $4.6 \%$ & $5.2 \%$ & $5.6 \%$ & $5.3 \%$ & $6.5 \%$ \\
\hline Very bad & $0.3 \%$ & $0 \%$ & $0 \%$ & $0.4 \%$ & $0.6 \%$ & $0 \%$ & $0 \%$ & $0.7 \%$ \\
\hline $\begin{array}{l}\text { Currently } \\
\text { smoking }\end{array}$ & $13.3 \%$ & $10.3 \%$ & $10.2 \%$ & $12.6 \%$ & $13.6 \%$ & $3.4 \%$ & $17.2 \%$ & $24.5 \%$ \\
\hline $\begin{array}{l}\text { Drinking } 3 \text { or } \\
\text { more units of } \\
\text { alcohol daily }\end{array}$ & $6.2 \%$ & $2.1 \%$ & $1.5 \%$ & $7.8 \%$ & $9.9 \%$ & $5.8 \%$ & $8.6 \%$ & $7.6 \%$ \\
\hline Test-retest & $91.3 \%$ & $90.6 \%$ & $97.0 \%$ & $89.8 \%$ & $92.9 \%$ & $89.0 \%$ & $90.8 \%$ & $87.0 \%$ \\
\hline $\begin{array}{l}\text { Task difficulty } \\
\text { (range } 1-7 \text { ) }\end{array}$ & 3.08 & 3.23 & 2.43 & 3.37 & 3.64 & 2.73 & NA & 2.91 \\
\hline
\end{tabular}

$N A$ not available

among smokers, $28.1 \%$ were not ready to change and among drinkers, $28.8 \%$ were not ready to change (data not shown).

The average score of difficulty of the task was 3.08 (country range: $2.43-3.64$ ). A total of $91.3 \%$ of respondents (country range: $87.0-97.0 \%$ ) chose the same alternative in the test-retest exercise. 


\section{Patients' preferences}

The results of the conditional logit model are presented in Table 3. Figure 2 displays estimates of patient preferences for the global model. Overall, patients felt positively about lifestyle behaviours for preventing osteoporosis fractures (positive and significant coefficients of the constant in the global model as well as in all countries separately). Regarding specific lifestyle behaviours in all countries, patients preferred moderate physical activity (i.e., walking for 15-20 min, 1-2 times per week) compared with not involving physical activity in a lifestyle package. However, patients were not prone to engage in a high level of physical activity (i.e., walking for 30-40 min, 3-4 times per week or equivalent). Regarding dietary nutritional behaviour, patients in all countries preferred taking daily calcium and vitamin D tablets over ensuring their diet was rich in calcium and vitamin D. However, Irish, Belgian, Swiss, Dutch and Spanish patients were not prone to modifying their nutrition (i.e., a diet rich in calcium and consumption of fish at least twice a week) or to ensure exposure to sunlight for 10-15 min daily. In the UK, Belgium and the Netherlands, we observed that patients intended to reduce their alcohol consumption and quit smoking. As for healthy weight, patients in all countries showed their preference for maintaining healthy body weight and avoiding becoming overweight or underweight. Finally, patients from Belgium, the Netherlands, Spain and Switzerland were not willing to receive a leaflet with general advice on avoiding falls nor to participate in a fall prevention program.

The relative importance of each attribute is reported in Fig. 3 overall and by country, where in all countries except Ireland, physical activity, fall prevention and calcium/vitamin D status were the top three important attributes.

\section{Subgroup analyses}

Subgroup analyses revealed no significant influence of gender, history of fracture and treatment of osteoporosis on patient preference for adopting lifestyle changes to prevent osteoporotic fractures. However, patients with a diagnosis of osteoporosis and patients aged 65 years or older were less prone to follow a lifestyle program $(p=0.03$ and $p<0.001$, respectively) (ESM Appendix 2).

\section{Discussion}

With this study, we show that globally, patients with or at risk of osteoporosis feel positively, in theory, towards undertaking lifestyle behaviour actions to prevent osteoporotic fracture. They are particularly positive about engaging in light to moderate physical activity, taking supplements of calcium or/and vitamin $\mathrm{D}$, reducing their alcohol consumption and maintaining/ensuring a healthy body weight. However, they seem more recalcitrant about engaging in a higher level of physical activity (i.e., walking for 30-40 min, 3-4 times per week), adhering to a diet rich in dairy products, consuming fish at least twice a week and ensuring exposure to sunlight for at least 15 min per day, as well as to participating in a 1-day fall prevention program.

In international guidelines and recommendations for osteoporosis management [6, 8-11,27, 28], exercising is considered to be one of the best practices for managing osteoporosis and preventing fractures. Although the benefits of exercising are clear with regard to osteoporosis, it is not surprising to observe, in our preference study, a positive intention from patients to engage in light to moderate physical activity and a more negative intention regarding a higher level of physical activity. Indeed, it is challenging for many people with or at risk of osteoporosis to initiate and adhere to an exercise program [29, 30]. A recent survey investigated exercise preferences for people with osteoporosis and identified barriers and facilitators for such preventive behaviours with regard to osteoporotic fracture [31]. Among the most common reasons for not being able to exercise and maintain an exercise program, patients cited pain when exercising, not liking exercise, fear of injuries but also the weather or the presence of concomitant diseases besides their osteoporosis that prevent them from exercising. This same study, on patient's preferences, underlined that participants preferred exercising at home in the morning, on their own schedule, with easy to perform exercise, slow paced and easy to remember. Patients also reported the importance of social support, even if they preferred exercising alone. Taking all those patient preferences into account when proposing exercises to protect their bone health could lead to higher initiation of and adherence to a physical activity program.

In addition to exercising, dietary measures should also be considered for any patients suffering from or at risk of osteoporosis. Recommendations include a daily calcium intake of between 800 and $1200 \mathrm{mg}$ and sufficient dietary proteins, ideally achieved through dairy products $[6,8,32$, 33]. Consumption of cheese and yogurt, for example, has been shown to reduce risk of hip fracture, through a recent meta-analysis pooling data from 18 individual studies [34]. Calcium and vitamin D supplementation is appropriate if dietary intake is insufficient $[6,8,32,35]$. The present study shows that patients seem more favourable to taking vitamin $\mathrm{D}$ and calcium supplements over ensuring that their diet is rich in calcium and vitamin $\mathrm{D}$, through the consumption of dairy products and fish. Literature reveals contrasting views on that. On the one hand, a recent population-based survey has accurately underlined a preference for lifestyle behaviours over medications for patients, especially for women, non-smokers and physically active participants [18]. Taking 


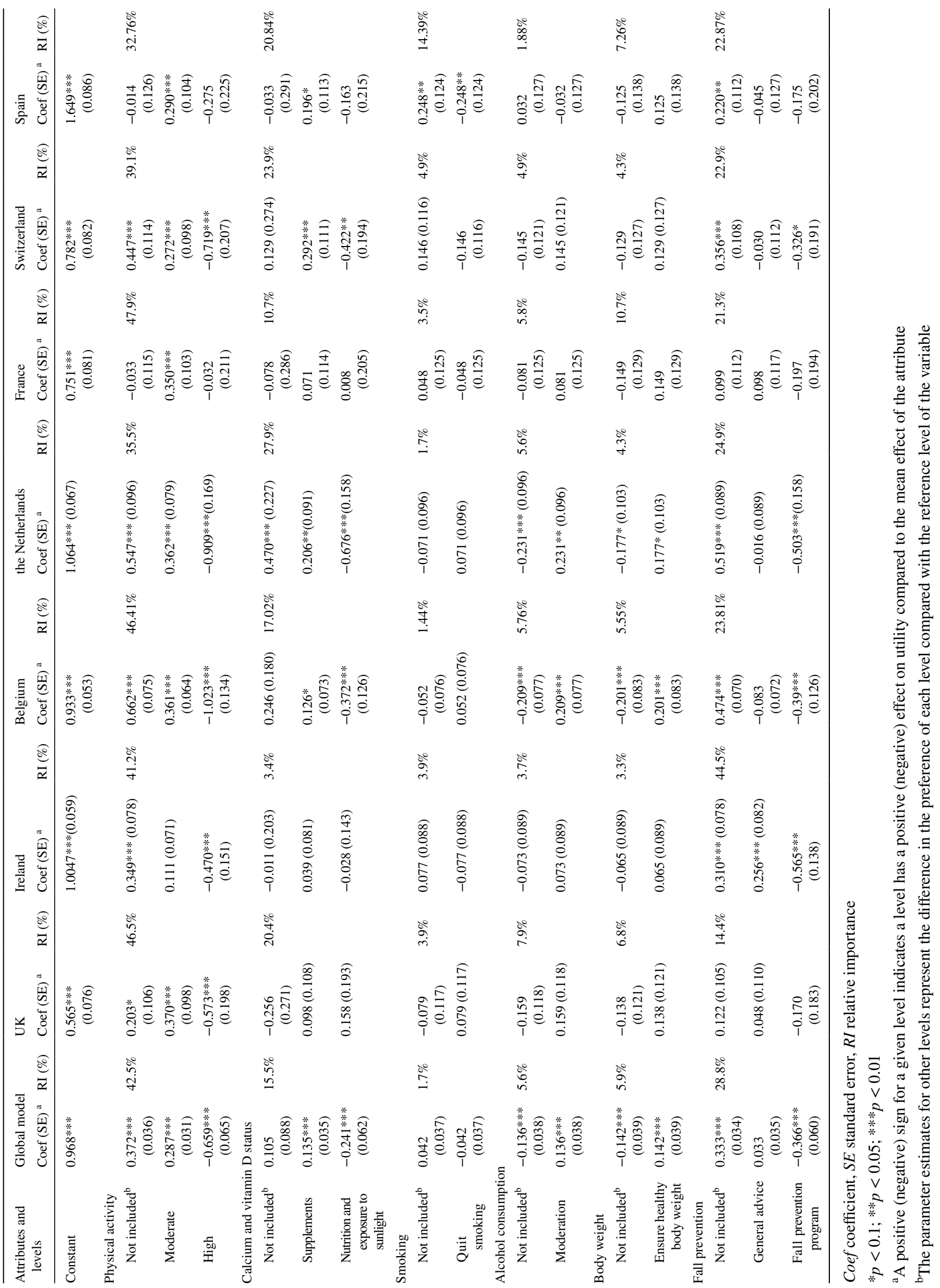


medicines or supplements may be considered as intrusive in daily living, and is accompanied with the fear of side effects, as well as changing the subject's self-concept from that of a healthy person to a sick person [36]. All of these reasons usually impede initiation to treatment. On the other hand, diet modification has always been considered to be challenging for humans. Moreover, ageing is also associated with a certain decline in food intake, loss of appetite/anorexia and loss of the motivation to eat $[37,38]$. The source of this anorexia is multifactorial and includes physiological changes but also the environmental and social modifications that come with ageing [37, 38]. Moreover, ageing has a negative effect on calcium and vitamin D absorption [39] and higher consumption of dairy products and fish is therefore necessary for this population to achieve the recommended levels, a course which is not always acceptable for patients. Therefore, it seems 'easier' and an acceptable alternative to take daily supplements. In our study, we found that patients in every country preferred taking vitamin $\mathrm{D}$ and calcium supplements over ensuring their appropriate dietary consumption, with the exception of the UK. However, we do not have a strong hypothesis to explain that UK participants seem more favourable than participants from other countries to ensure adequate consumption of vitamin $\mathrm{D}$ and calcium via diet.

Among the lifestyle behaviours investigated in our study, we also investigated whether participants were willing to receive either advice on fall prevention or to participate in a 1-day fall prevention course. Consensually, all countries were not willing to attend a 1-day fall prevention course. It has already been shown that participation rates in a fall prevention program are usually low [40]. Older adults may be not aware of their risk of falling, may perceive a fall prevention program as being irrelevant or may simply not be inclined to participate in a fall prevention program due to personal factors (e.g., transportation, costs) [41]. A goodquality doctor-patient communication should be prioritised here to make patients aware of their individual risk of falls. Accordingly, providing participants with advice on reducing the risk of falling could be a good start. A former best-worst scaling performed with prostate cancer survivors has indeed revealed that patients preferred receiving advice on health through one-to-one discussion with their healthcare professional over group discussion, email or telephone conversations [42].

Other lifestyle behaviours have been investigated in the current study, such as reducing alcohol consumption, quitting smoking and ensuring a healthy body weight. Globally, these recommendations were not considered as the most important ones for participants as their relative importance was, respectively, $5.6 \%, 1.7 \%$ and $5.9 \%$ in the global model, partly resulting from the small percentage of smokers or with the relative importance of alcohol consumption. Reducing alcohol consumption seems to be acceptable for most of the participants. With the exception of patients from Spain, all coefficients of other countries were positive. Nor were Spanish patients prone to quit smoking. In Spain, the prevalence of smokers is the highest (i.e., $25 \%$ of the sample) which may explain the higher non-acceptance for changing this lifestyle behaviour. However, smoking cessation is important in osteoporosis/osteoporosis fracture prevention. Evidence has shown that tobacco may cause an imbalance in the mechanisms of bone turnover, reducing bone mass and bone mineral density [43-45]. Similar to alcohol consumption, a recent meta-analysis underlined a linear relationship between the consumption of alcohol and the risk of osteoporosis, with higher risk for persons who consumed more alcohol. For example, persons consuming two drinks or more per day had 1.63 times the risk of developing osteoporosis compared to non-drinkers [46]. Finally, participants were asked if they would accept ensuring a healthy body weight, defined by avoiding becoming overweight or underweight. In our study, patients seem favourable to this recommendation. In literature, the relationship between body mass index (BMI) and the risk of fracture is still obscure and complex. The risk may differ across skeletal sites and seems modified by the interaction between BMI and bone mineral density (BMD). At a population level, different meta-analyses have underlined that a high BMI (as well as obesity) seem to be a protective factor for most sites of fragility fracture [47-49]. On the contrary, low BMI seems to increase fracture risk, possibly because low BMI is associated with low BMD, less soft tissue and muscle weakness [50]. So, underweight should definitely be avoided, but the public health message about overweight as a protective factor for fractures remains complex.

\section{Limitations and future perspectives}

As all studies, our study has a number of limitations that should be considered when interpreting the results. First, an inherent limitation of a DCE is that it assesses hypothetical behaviours. Even if patients claimed to be favourable towards some lifestyle behavioural changes, none could guarantee that they would implement such a choice in real life. While DCEs are widely used, social desirability may also have a disturbing role in these studies. A future study comparing stated preferences with actual choice data in osteoporosis would be interesting to elicit potential differences between theoretical choices and real choices. Moreover, the quantitative approach of a DCE does not allow in-depth investigation of all the personal reasons (beliefs, experience, etc.) underlying why patients do not want to adhere to lifestyle programs. Further qualitative research may provide additional important data to better and deeper understand patient preferences and expectations for lifestyle programs. 
Fig. 2 Estimates of patient preferences for the global model

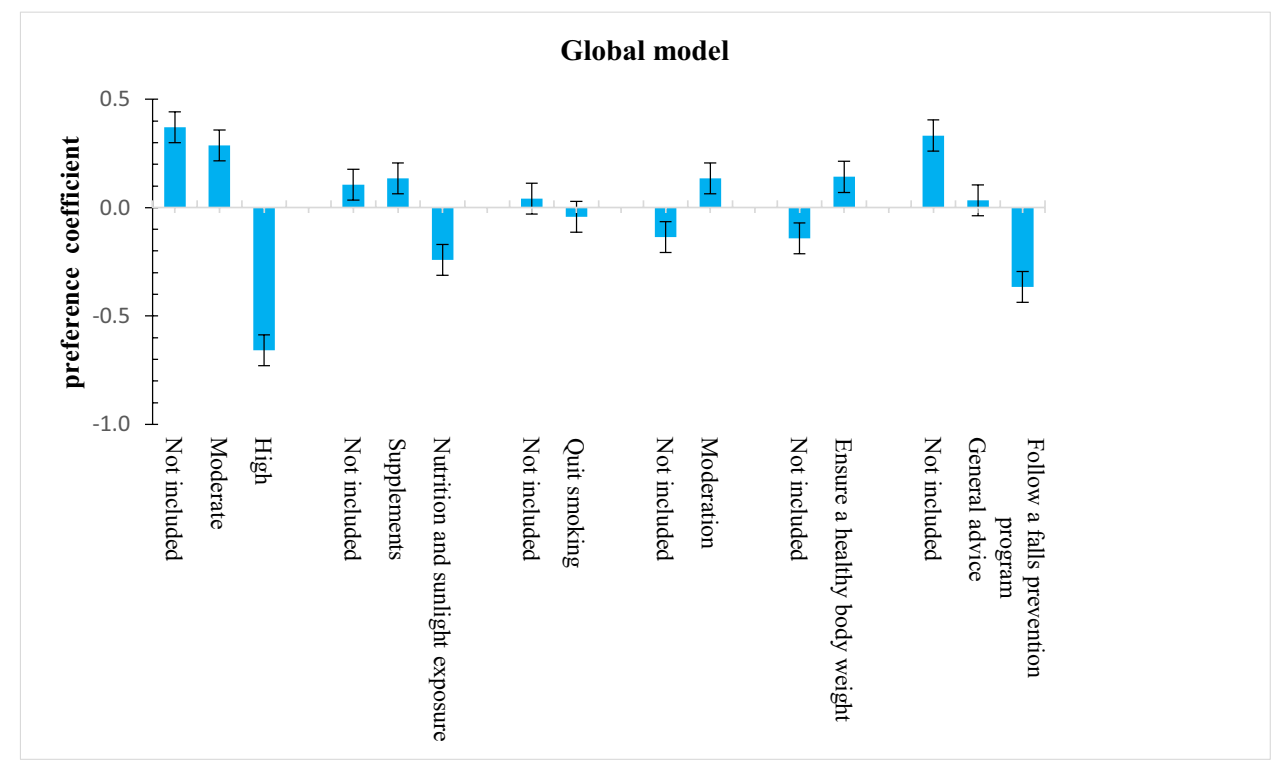

Fig. 3 Relative importance of attributes (in percentage) for all participants and per country

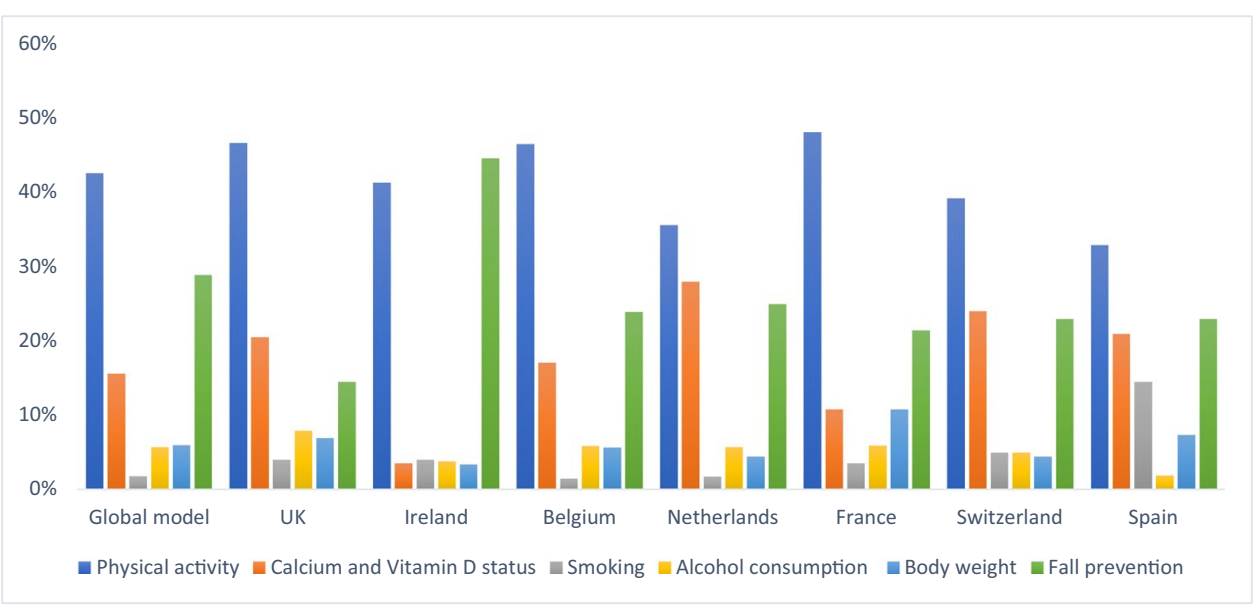

Nevertheless, the present study does provide initial and useful information for optimal non-pharmaceutical osteoporosis management. Awareness of variation in preferences for lifestyle is very insightful for healthcare professionals when starting communication with a patient regarding lifestyle. Second, data collection was performed in 2012, 10 years ago. Health behaviours could vary across years, with developments in health/scientific research and improvement in treatments. It cannot be excluded that patient's preferences could have changed over the course of years. However, the recommendations addressed in our study are still the most important recommendations from current scientific entities. Third, although we conducted a large international study, we included only western European countries. The extrapolation of our results to countries from eastern European countries and outside Europe may be uncertain, especially as patients from these countries may have different socio-economic, medical and cultural backgrounds and thus other preferences for lifestyle interventions. Moreover, in most countries, the study was conducted in only one centre, which could reduce the generalisability to the whole country. Still in the same vein, we investigated differences between countries, but did not go further to investigate the influence of latitude or season of the year on some of the attributes (e.g., willingness to engage in physical activity, willingness to ensure a minimum exposure to sunlight). Finally, to optimise patient's completion of the questionnaire and efficient designs for analyses, we used a limited number of attributes and levels in this DCE. Even if additional lifestyle behaviours could have been recommended, we had to limit our investigation around the attributes and levels that we considered to be the most important/relevant ones. It is highly probable that the use of other or additional attributes in this study may have led to different results. 


\section{Conclusions}

Healthy lifestyle behaviours are an essential part of optimal osteoporosis management. To our knowledge, this study is the first to assess patient preferences for lifestyle factors in preventing osteoporotic fracture. Results suggest that patients are favourable towards adapting some lifestyle behaviours to prevent osteoporotic fractures. In particular, patients seem willing to reduce their alcohol consumption, engage in moderate physical activity, initiate calcium and vitamin D supplementation and ensure a normal body weight. In a patient-centred approach, clinicians should engage in a conversation with patients to ensure patients can make informed choices for lifestyle changes that fit their medical needs as well as their preferences and beliefs. Decision aids can support this decision process. This will be only the first step towards implementing desired lifestyle behaviour. Innovative interventions (e.g., computer-tailored e-health tools) to support behavioural change and thus strengthen adherence to the chosen lifestyle will be necessary and are an area for future research in person-centred care in the prevention of osteoporosis.

Supplementary Information The online version contains supplementary material available at https://doi.org/10.1007/s00198-022-06310-4.

Acknowledgements We would like to thank all participating centres: the Unit for Osteoporosis and Metabolic Bone from Ghent University Hospital (Belgium); the University Center for Investigation in Bone and Articular Cartilage Metabolism in Liège (Belgium); the Fracture Clinic of Maastricht University Medical Center (the Netherlands); the Bone Unit of Paris Descartes University, Paris (France); the North Western Rheumatology Unit, Our Lady's Hospital, Manorhamilton and Sligo University Hospital (Ireland); the Musculoskeletal Research Unit and RETICEF from the Universitat Autònoma de Barcelona (Spain); the Division of Bone Diseases from the Geneva University Hospitals (Switzerland); the MRC Lifecourse Epidemiology Unit from the University of Southampton (UK) for helping us in data collection; Ed Porquie, our patient partner; Wafa Ben Sedrine, Ivette Essers and Wilco Tilburgs for data entry; and all the patients for their participation.

Funding This study was part of a project funded by Amgen. The funding agreement between Maastricht University and Amgen ensured the authors' independence in designing the study (including selection of attributes and levels), interpreting the data, and writing and publishing the report. Other participating centres were compensated by Maastricht University for their participation in the study.

Data availability All data are available on request to the corresponding author.

\section{Declarations}

Ethics Approval for this study was obtained from the Medical Ethics Committee of the Academic Hospital Maastricht and Maastricht University. Additional local ethics approval was obtained from those participating centres that required ethics approval for a DCE study, i.e., the Research Ethics Committee of Sligo University Hospital, the Southampton Joint Ethics Committee, the CEIC-Parc de Salut Mar
(Committee of Ethics and Clinical Investigation) and the 'Commission cantonale d'éthique de la recherche' (CCER) of Geneva.

Conflicts of interest JYR has received research grant and/or consulting fees from Servier, Novartis, Negma, Lilly, Wyeth, Amgen, GlaxoSmithKline, Roche, Merckle, Nycomed-Takeda, NPS, IBSA Genevrier, Theramex, UCB, Asahi Kasei, Endocyte, Merck Sharp and Dohme, Rottapharm, Teijin, Teva, Analis, NovoNordisk, Ebewee Pharma, Zodiac, Danone, Will Pharma, Meda, Bristol Myers Squibb, Pfizer, Organon, Therabel, Boehringer, Chiltern, Galapagos. SG has received lecture fees from Amgen and consulting fees from the advisory board of UCB. AD-P has been a speaker or advisor for Amgen, Lilly, Theramex and Active Life Scientific. RR has received consulting fees from the advisory boards of Abiogen, Amgen, Danone, Echolight, European Milk Forum, Nestlé, ObsEva, Pfizer Consumer Health, Radius Health and Theramex. BW has received speaker or consulting fees from advisory boards of Abbvie, Pfizer, Merck Sharp and Dohme, Menarini and Novartis Pharmaceuticals. The remaining authors state that they have no competing interests relevant to this study.

Open Access This article is licensed under a Creative Commons Attribution-NonCommercial 4.0 International License, which permits any non-commercial use, sharing, adaptation, distribution and reproduction in any medium or format, as long as you give appropriate credit to the original author(s) and the source, provide a link to the Creative Commons licence, and indicate if changes were made. The images or other third party material in this article are included in the article's Creative Commons licence, unless indicated otherwise in a credit line to the material. If material is not included in the article's Creative Commons licence and your intended use is not permitted by statutory regulation or exceeds the permitted use, you will need to obtain permission directly from the copyright holder. To view a copy of this licence, visit http://creativecommons.org/licenses/by-nc/4.0/.

\section{References}

1. Borgström F, Karlsson L, Ortsäter G et al (2020) Fragility fractures in Europe: burden, management and opportunities. Arch Osteoporos. https://doi.org/10.1007/s11657-020-0706-y

2. Hernlund E, Svedbom A, Ivergård M et al (2013) Osteoporosis in the European Union: medical management, epidemiology and economic burden: a report prepared in collaboration with the International Osteoporosis Foundation (IOF) and the European Federation of Pharmaceutical Industry Associations (EFPIA). Arch Osteoporos. https://doi.org/10.1007/s11657-013-0136-1

3. Reginster JY, Burlet N (2006) Osteoporosis: a still increasing prevalence. Bone 38:4-9. https://doi.org/10.1016/j.bone.2005. 11.024

4. Li N, Cornelissen D, Silverman S et al (2021) An updated systematic review of cost-effectiveness analyses of drugs for osteoporosis. Pharmacoeconomics 39:181-209. https://doi.org/10.1007/ s40273-020-00965-9

5. Kanis JA, Brazier JE, Stevenson M et al (2002) Treatment of established osteoporosis: a systematic review and cost-utility analysis. Health Technol Assess (Rockv). https://doi.org/10.3310/ hta6290

6. Kanis JA, Cooper C, Rizzoli R, Reginster JY (2019) Executive summary of the European guidance for the diagnosis and management of osteoporosis in postmenopausal women. Calcif Tissue Int 104:235-238. https://doi.org/10.1007/s00223-018-00512-x

7. Barrionuevo P, Kapoor E, Asi N et al (2019) Efficacy of pharmacological therapies for the prevention of fractures in 
postmenopausal women: a network meta-analysis. J Clin Endocrinol Metab 104:1623-1630. https://doi.org/10.1210/JC. 2019-00192

8. Kanis JA, Cooper C, Rizzoli R, Reginster JY (2019) European guidance for the diagnosis and management of osteoporosis in postmenopausal women. Osteoporos Int 30:3-44. https://doi.org/ 10.1007/s00198-018-4704-5

9. Camacho PM, Petak SM, Binkley N et al (2020) American Association of Clinical Endocrinologists/American College of Endocrinology clinical practice guidelines for the diagnosis and treatment of postmenopausal osteoporosis-2020 update. Endocr Pract 26:1-46. https://doi.org/10.4158/GL-2020-0524SUPPL

10. Cummings SR, Cosman F, Lewiecki EM et al (2017) Goaldirected treatment for osteoporosis: a progress report from the ASBMR-NOF Working Group on Goal-Directed Treatment for Osteoporosis. J Bone Miner Res 32:3-10. https://doi.org/10.1002/ jbmr.3039

11. Buckley L, Guyatt G, Fink HA et al (2017) 2017 American College of Rheumatology guideline for the prevention and treatment of glucocorticoid-induced osteoporosis. Arthritis Care Res 69:1095-1110. https://doi.org/10.1002/acr.23279

12. Body JJ, Bergmann P, Boonen S et al (2011) Non-pharmacological management of osteoporosis: a consensus of the Belgian Bone Club. Osteoporos Int 22:2769-2788. https://doi.org/10.1007/ s00198-011-1545-x

13. Rizzoli R, Stevenson JC, Bauer JM et al (2014) The role of dietary protein and vitamin $\mathrm{D}$ in maintaining musculoskeletal health in postmenopausal women: a consensus statement from the European Society for Clinical and Economic Aspects of Osteoporosis and Osteoarthritis (ESCEO). Maturitas 79:122-132. https://doi. org/10.1016/j.maturitas.2014.07.005

14. McMillan LB, Zengin A, Ebeling PR, Scott D (2017) Prescribing physical activity for the prevention and treatment of osteoporosis in older adults. Healthcare 5:85. https://doi.org/10.3390/HEALT HCARE5040085

15. Rizzoli R, Biver E, Brennan-Speranza TC (2021) Nutritional intake and bone health. Lancet Diabetes Endocrinol 9:606-621. https://doi.org/10.1016/S2213-8587(21)00119-4

16. Lakerveld J, IJzelenberg W, Van Tulder MW et al (2008) Motives for (not) participating in a lifestyle intervention trial. BMC Med Res Methodol. https://doi.org/10.1186/1471-2288-8-17

17. Owen K, Pettman T, Haas M et al (2010) Individual preferences for diet and exercise programmes: changes over a lifestyle intervention and their link with outcomes. Public Health Nutr 13:245252. https://doi.org/10.1017/S1368980009990784

18. Jarbøl DE, Larsen PV, Gyrd-Hansen D et al (2017) Determinants of preferences for lifestyle changes versus medication and beliefs in ability to maintain lifestyle changes. A population-based survey. Prev Med Reports 6:66-73. https://doi.org/10.1016/J.PMEDR. 2017.02.010

19. Gasperini B, Cherubini A, Montanari R et al (2021) How much do patients know about osteoporosis? A survey among patients referred to the dual-energy X-ray absorptiometry exam. Aging Clin Exp Res 1-7. https://doi.org/10.1007/s40520-021-01860-9

20. Veldwijk J, Lambooij MS, Van Gils PF et al (2013) Type 2 diabetes patients' preferences and willingness to pay for lifestyle programs: a discrete choice experiment. BMC Public Health 13:1099. https://doi.org/10.1186/1471-2458-13-1099

21. Mühlbacher A, Bethge S (2013) Preferences of overweight and obese patients for weight loss programs: a discrete-choice experiment. Int J Integr Care. https://doi.org/10.5334/ijic.1113

22. Wright SJ, Gibson D, Eden M et al (2017) What are colorectal cancer survivors' preferences for dietary advice? A best-worst discrete choice experiment. J Cancer Surviv 11:782-790. https:// doi.org/10.1007/s11764-017-0615-2
23. Bridges JFP, Hauber AB, Marshall D et al (2011) Conjoint analysis applications in health - a checklist: a report of the ISPOR Good Research Practices for Conjoint Analysis Task Force. Value Heal 14:403-413. https://doi.org/10.1016/j.jval.2010.11.013

24. Hiligsmann M, Dellaert BG, Dirksen CD et al (2017) Patients' preferences for anti-osteoporosis drug treatment: a cross-European discrete choice experiment. Rheumatology (United Kingdom) 56:1167-1176. https://doi.org/10.1093/rheumatology/kex071

25. Lancsar E, Louviere J (2008) Conducting discrete choice experiments to inform healthcare decision making. Pharmacoeconomics 26:661-677. https://doi.org/10.2165/00019053-200826080-00004

26. de Bekker-Grob EW, Donkers B, Jonker MF, Stolk EA (2015) Sample size requirements for discrete-choice experiments in healthcare: a practical guide. Patient Patient-Centered Outcomes Res 8:373-384. https://doi.org/10.1007/s40271-015-0118-z

27. Hiligsmann M, Cornelissen D, Vrijens B et al (2019) Determinants, consequences and potential solutions to poor adherence to anti-osteoporosis treatment: results of an expert group meeting organized by the European Society for Clinical and Economic Aspects of Osteoporosis, Osteoarthritis and Musculoskeletal. Osteoporos Int 30:2155-2165. https://doi.org/10.1007/ s00198-019-05104-5

28. Thomas E, Gentile A, Lakicevic N et al (2021) The effect of resistance training programs on lean body mass in postmenopausal and elderly women: a meta-analysis of observational studies. Aging Clin Exp Res. https://doi.org/10.1007/s40520-021-01853-8

29. Kemmler W, von Stengel S, Kohl M (2016) Exercise frequency and bone mineral density development in exercising postmenopausal osteopenic women. Is there a critical dose of exercise for affecting bone? Results of the Erlangen Fitness and Osteoporosis Prevention Study. Bone 89:1-6. https://doi.org/10.1016/j.bone. 2016.04.019

30. Kemmler W, von Stengel S, Kohl M (2017) Exercise frequency and fracture risk in older adults-how often is enough? Curr Osteoporos Rep 15:564-570. https://doi.org/10.1007/ s11914-017-0407-7

31. Ziebart C, MacDermid J, Szekeres M et al (2020) Barriers, facilitators, needs and goals of exercise for people with osteoporosis. Med Sci Sport Exerc 52:417-417. https://doi.org/10.1249/01.mss. 0000678400.39345.e8

32. Rizzoli R, Boonen S, Brandi M-L et al (2013) Vitamin D supplementation in elderly or postmenopausal women: a 2013 update of the 2008 recommendations from the European Society for Clinical and Economic Aspects of Osteoporosis and Osteoarthritis (ESCEO). Curr Med Res Opin 29:305-313. https://doi.org/10. 1185/03007995.2013.766162

33. Rizzoli R, Biver E, Bonjour JP et al (2018) Benefits and safety of dietary protein for bone health-an expert consensus paper endorsed by the European Society for Clinical and Economical Aspects of Osteopororosis, Osteoarthritis, and Musculoskeletal Diseases and by the International Osteoporosis Fou. Osteoporos Int 29:1933-1948. https://doi.org/10.1007/s00198-018-4534-5

34. Bian S, Hu J, Zhang K et al (2018) Dairy product consumption and risk of hip fracture: a systematic review and meta-analysis. BMC Public Health. https://doi.org/10.1186/s12889-018-5041-5

35. Rizzoli R (2021) Vitamin D supplementation: upper limit for safety revisited? Aging Clin Exp Res 33:19-24. https://doi.org/ 10.1007/s40520-020-01678-x

36. Horne R, Weinman J (1999) Patients' beliefs about prescribed medicines and their role in adherence to treatment in chronic physical illness. J Psychosom Res 47:555-567. https://doi.org/ 10.1016/S0022-3999(99)00057-4

37. Donini LM, Savina C, Cannella C (2003) Eating habits and appetite control in the elderly: the anorexia of aging. Int Psychogeriatrics 15:73-87. https://doi.org/10.1017/S1041610203008779 
38. Giezenaar C, Chapman I, Luscombe-Marsh N et al (2016) Ageing is associated with decreases in appetite and energy intake- a meta-analysis in healthy adults. Nutrients. https://doi.org/10.3390/ nu8010028

39. Bullamore JR, Wilkinson R, Gallagher JC et al (1970) Effect of age on calcium absorption. Lancet 296:535-537. https://doi.org/ 10.1016/S0140-6736(70)91344-9

40. Merom D, Pye V, Macniven R et al (2012) Prevalence and correlates of participation in fall prevention exercise/physical activity by older adults. Prev Med (Baltim) 55:613-617. https://doi.org/ 10.1016/j.ypmed.2012.10.001

41. Elskamp ABM, Hartholt KA, Patka P et al (2012) Why older people refuse to participate in falls prevention trials: a qualitative study. Exp Gerontol 47:342-345. https://doi.org/10.1016/j.exger. 2012.01.006

42. Robles LA, Wright SJ, Hackshaw-Mcgeagh L et al (2020) Prostate cancer survivors' preferences on the delivery of diet and lifestyle advice: a pilot best-worst discrete choice experiment. Pilot Feasibility Stud. https://doi.org/10.1186/s40814-019-0549-8

43. Cusano NE (2015) Skeletal effects of smoking. Curr Osteoporos Rep 13:302-309. https://doi.org/10.1007/s11914-015-0278-8

44. Ward KD, Klesges RC (2001) A meta-analysis of the effects of cigarette smoking on bone mineral density. Calcif Tissue Int 68:259-270. https://doi.org/10.1007/BF02390832

45. Al-Bashaireh AM, Haddad LG, Weaver M et al (2018) The effect of tobacco smoking on musculoskeletal health: a systematic review. J Environ Public Health. https://doi.org/10.1155/2018/ 4184190
46. Cheraghi Z, Doosti-Irani A, Almasi-Hashiani A et al (2019) The effect of alcohol on osteoporosis: a systematic review and metaanalysis. Drug Alcohol Depend 197:197-202. https://doi.org/10. 1016/j.drugalcdep.2019.01.025

47. Turcotte AF, O'Connor S, Morin SN et al (2021) Association between obesity and risk of fracture, bone mineral density and bone quality in adults: a systematic review and meta-analysis. PLoS ONE 16:e0252487. https://doi.org/10.1371/journal.pone. 0252487

48. Xiang BY, Huang W, Zhou GQ et al (2017) Body mass index and the risk of low bone mass-related fractures in women compared with men: a PRISMA-compliant meta-analysis of prospective cohort studies. Medicine (United States). https://doi.org/10.1097/ MD.0000000000005290

49. De Laet C, Kanis JA, Odén A et al (2005) Body mass index as a predictor of fracture risk: a meta-analysis. Osteoporos Int 16:1330-1338. https://doi.org/10.1007/s00198-005-1863-y

50. Nielson CM, Srikanth P, Orwoll ES (2012) Obesity and fracture in men and women: an epidemiologic perspective. J Bone Miner Res 27:1-10. https://doi.org/10.1002/jbmr.1486

Publisher's Note Springer Nature remains neutral with regard to jurisdictional claims in published maps and institutional affiliations.

\section{Authors and Affiliations}

\section{Beaudart ${ }^{1}$ (D) A. Boonen ${ }^{2} \cdot$ N. Li ${ }^{1} \cdot$ S. Bours ${ }^{1} \cdot$ S. Goemaere ${ }^{3} \cdot$ J.-Y. Reginster ${ }^{4} \cdot$ C. Roux ${ }^{5} \cdot$ B. McGowan ${ }^{6}$. A. Diez-Perez ${ }^{7} \cdot$ R. Rizzoli ${ }^{8} \cdot$ C. Cooper ${ }^{9} \cdot$ M. Hiligsmann ${ }^{1}$}

1 Department of Health Services Research, CAPHRI Care and Public Health Research Institute, Maastricht University, Maastricht, the Netherlands

2 Division of Rheumatology, Department of Internal Medicine, and CAPRHI Care and Public Health Research Institute, Maastricht University Medical Center, Maastricht, the Netherlands

3 Department of Rheumatology and Endocrinology, Ghent University Hospital, Ghent, Belgium

4 WHO Collaborating Center for Public Health Aspects of Musculo-Skeletal Health and Ageing, Division of Public Health, Epidemiology and Health Economics, University of Liège, Liège, Belgium
5 Department of Rheumatology, Paris Descartes University, Paris, France

6 The North Western Rheumatology Unit, Our Lady's Hospital, Manorhamilton, Co. Leitrim, Ireland

7 Musculoskeletal Research Unit (IMIM) and CIBERFES, Universitat Autònoma de Barcelona, Barcelona, Spain

8 Division of Bone Diseases, Geneva University Hospitals and Faculty of Medicine, Geneva, Switzerland

$9 \quad$ MRC Lifecourse Epidemiology Unit, University of Southampton, Southampton General Hospital, Southampton, UK 